\title{
Towards developing value strategies to improve contact efficiency of Web sites: a marketing perspective
}

J. Nel

Department of Business Management, University of the Free State, South Africa

Nelj@ekn.ekwet.uovs.ac.za

\section{M.J. Crous}

Department of Business Management, University of the Free State, South Africa

G.J.P. Human

VISIMED, Bloemfontein, South Africa

\section{Content}

1. Introduction

2. Importance of value in a Web site

3. Advertising value and advertising on the World-Wide Web

4. Approach 1: information, entertainment and purchase facilitation

5. Approach 2: Gascoyne's complete customer-centric solution

6. Conclusion

7. References

\section{Introduction}

The Internet has received a great deal of attention in the media lately due to the tremendous growth among consumers and businesses alike. Furthermore, the acceptance and usage of the Internet is so phenomenal that many experts are having difficulty in monitoring its growth (Bush, Bush and Harris, 1998:17). NUA Internet surveys, as depicted in Figure 1, estimate that the number of Internet users may still increase to about 350 million world-wide by the year 2005. According to Hanson (1999:17), this growth in Internet users creates opportunities for businesses to develop new services and brands.

Figure 1 Number of Internet users 


\section{How Many Online Worldwide}

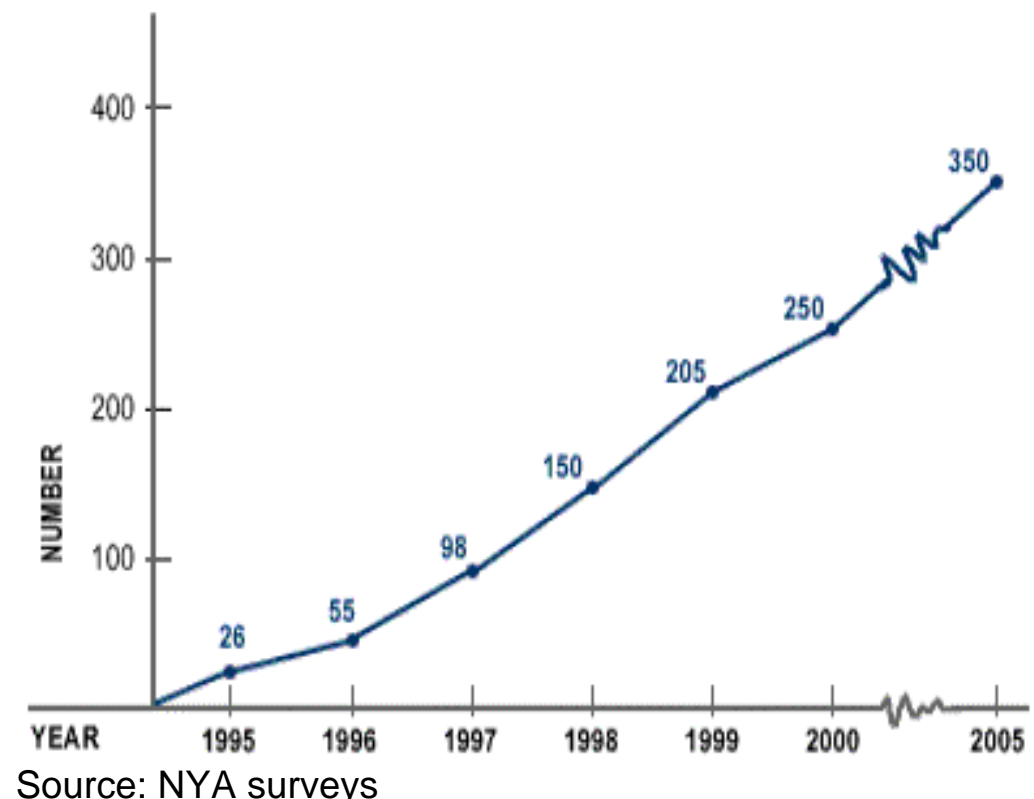

In contrast with the high expectations of businesses, Bayers (as quoted by Schlosser and Kanfer, 1995/6:1) reports that many companies are becoming disillusioned with the commercial possibilities of on-line advertising. Moreover, some businesses have even suggested that the Internet is better suited for interpersonal communication and personal sites rather than commercial sites. As a result, executives are questioning whether the potential of the Internet is 'real' or just 'hype,' and some companies are even considering decreasing or removing their investment in on-line advertising.

According to Berthon, Pitt and Watson (1996:24) marketers and managers recognize by now, that a greater understanding of the true nature of commerce on the Web is required, particularly in respect of using it as a marketing communication medium. With this statement in mind, the objective of this article is to consider the development of value strategies in order to enhance the success of Web sites. According to Berthon et al. (1996:40), value is one of the factors that plays an important role in the overall efficiency of a Web site. The model of the conversion process on the Web explains the importance of value with regard to Web site efficiency.

\section{Importance of value in a Web site}

Berthon et al. (1996:43) introduced a conceptual framework for measuring the efficiency of a Web site. This framework (as depicted in Figure 2) proposes that the conversion process consists of six stages.

According to this model, value plays an important role in the contact efficiency stage. Contact efficiency measures the conversion of Web site 'hits' into 'visits'. A 'visit' compared to a 'hit' implies greater interaction between the surfer and the Web page. The structure of the model implies that the conversion rate of 'hits' into 'visits' may have an effect on converting 'hits' into purchasers of the product. Consequently, from a marketing perspective, the conversion rate of 'hits' into 'visits' need to be as high as possible. Therefore, marketers need to formulate suitable value strategies in order to provide value that encourages the customer to interact with the site. 
Figure 2 Model of the conversion process on the Web

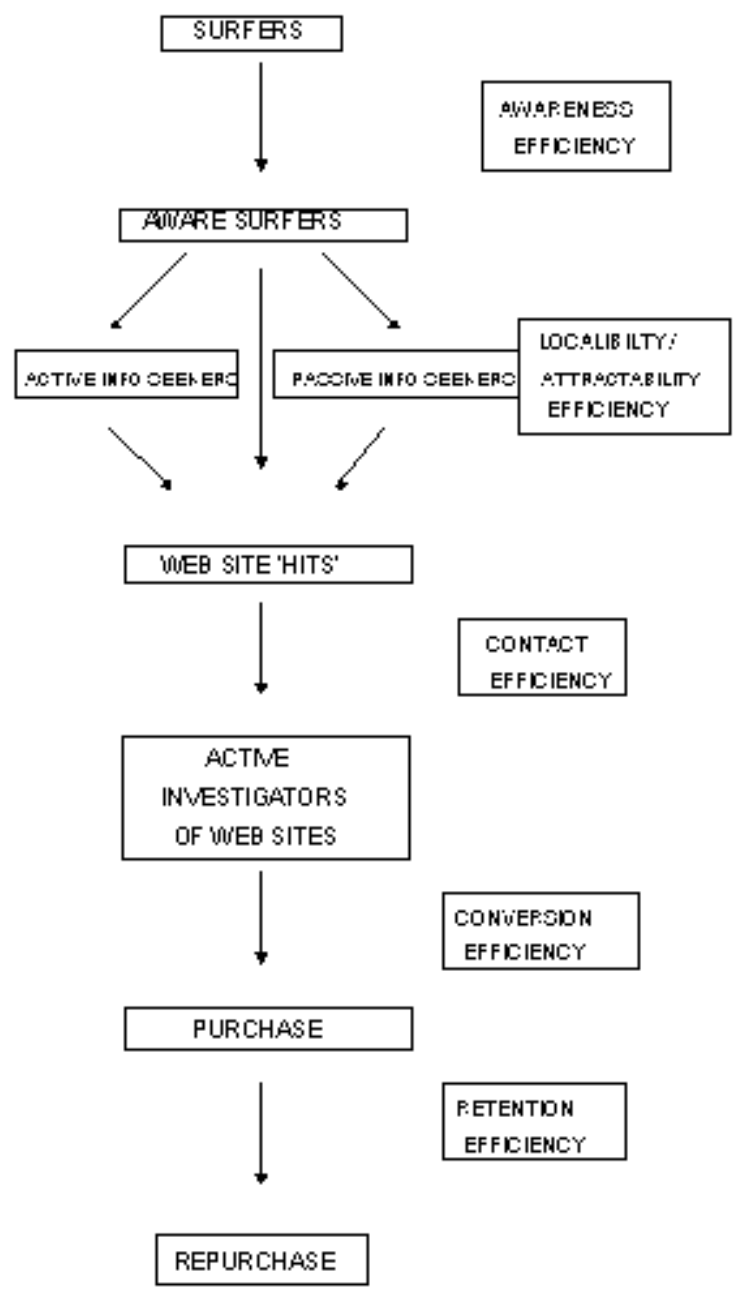

Source: Berthon, Pitt and Watson (1996:49)

\section{Advertising value and advertising on the World-Wide Web}

Richard Ducoffe recognized the importance of advertising value in traditional media. According to Ducoffe, advertising that the consumer considers valuable is more likely to yield the type of response required by the advertiser (Ducoffe, 1996:21). Ducoffe contributed to the understanding of advertising value by identifying the predictors of advertising value in the traditional media. These predictors are as follows:

- Informativeness: From a consumer's point of view, consensus exists with regard to the ability of advertising to inform consumers of product alternatives so that purchases yielding the greatest possible satisfaction can be made. According to Ducoffe (1996:22), consumers themselves report that the ability to supply information is the primary reason for approving of advertising.

- Entertainment: Research indicated that pleasant or likeable advertising is thought to have a positive impact on brand attitudes. In addition, uses and gratification research (Ducoffe,1996:22) has also demonstrated that the value of entertainment lies in its ability to fulfil audience needs for escapism, diversion, aesthetic enjoyment, or emotional release. As the value of media entertainment is regularly acknowledged, and as advertising is a significant portion of media content, the ability of advertising to entertain can enhance the experience of advertising exchanges for consumers.

- Irritation: When advertising employs techniques that annoy, offend, insult, or are 
overly manipulative, consumers are likely to perceive it as an unwanted or irritating influence. Accordingly Ducoffe's research also confirmed that irritation has a negative impact on advertising value.

Ducoffe also tested the relevancy of these three factors in Web advertising and confirmed that informativeness, entertainment and irritation are still important predictors of value in Web advertising.

As a result, this research of Ducoffe provides useful insight when developing value strategies. Applying the findings of Ducoffe's research the following can be concluded:

- The value strategy of a Web site should focus on providing information and/or entertainment.

- Irritation needs to be avoided as much as possible.

Two possible approaches for the development of value strategies were identified. In the following sections these two approaches will be explained and evaluated against the predictors of value on the Web identified by Ducoffe.

\section{Approach 1: information, entertainment and purchase facilitation}

The supporters of this approach suggest that the classification of products according to buyer involvement is an important dimension to consider before developing possible value strategies. According to buyer involvement, products can be classified in high-buyer involvement and low-buyer involvement products (Lamb, Hair and MacDaniel, 1996:122).

\subsection{Classification of products according to buyer behaviour}

One of the reasons for distinguishing between high- and low-buyer involvement is that habit, intuition and convenience sometimes guide the actions of consumers rather than rational and thorough consideration. High involvement products usually necessitate the consumer to search for product information, because of the economic and psychosocial risk associated with the purchase of the product (Lamb et al., 1996:122). Hence, consumers purchasing high-buyer involvement products do an extensive information search, due to the risk associated with the purchase (Lamb et al., 1996:122). However, with low-buyer involvement products, the consumer experiences less perceived risk, less identification with the product and less personal relevance (Lamb et al., 1996:122). Furthermore, problem recognition is not normally experienced until the consumer is exposed to advertising or sees an item displayed on the shelf. Thus, low-buyer involvement decision making is typical in habitual consumer behaviour, characterized by brand loyalty.

In brief, products may be classified in high-buyer involvement and low-buyer involvement products, because differences exist with regard to customer action when purchasing different types of products.

\subsection{Information strategy}

According to Barker and Groenne (1996:95), for products with a high degree of buyer involvement, the infomercial (providing information) might be an obvious method for creating customer value, drawing advantage from the fact that the customer is usually an active information seeker in this product category. According to the characteristics of highbuyer involvement products presented in the previous section, the Web site of a car 
manufacturer may be used as an example to illustrate the information strategy.

The Volkswagen South Africa Web site is a real world example of how product-related information can be used as a value strategy in a Web site. Supplying product related information is justified by classifying the purchase of a new car as a high-buyer involvement action, since there appears to be economic risk and sometimes social risk involved. The Volkswagen Golf page is presented in Figure 3.

Figure 3 Volkswagen Golf page

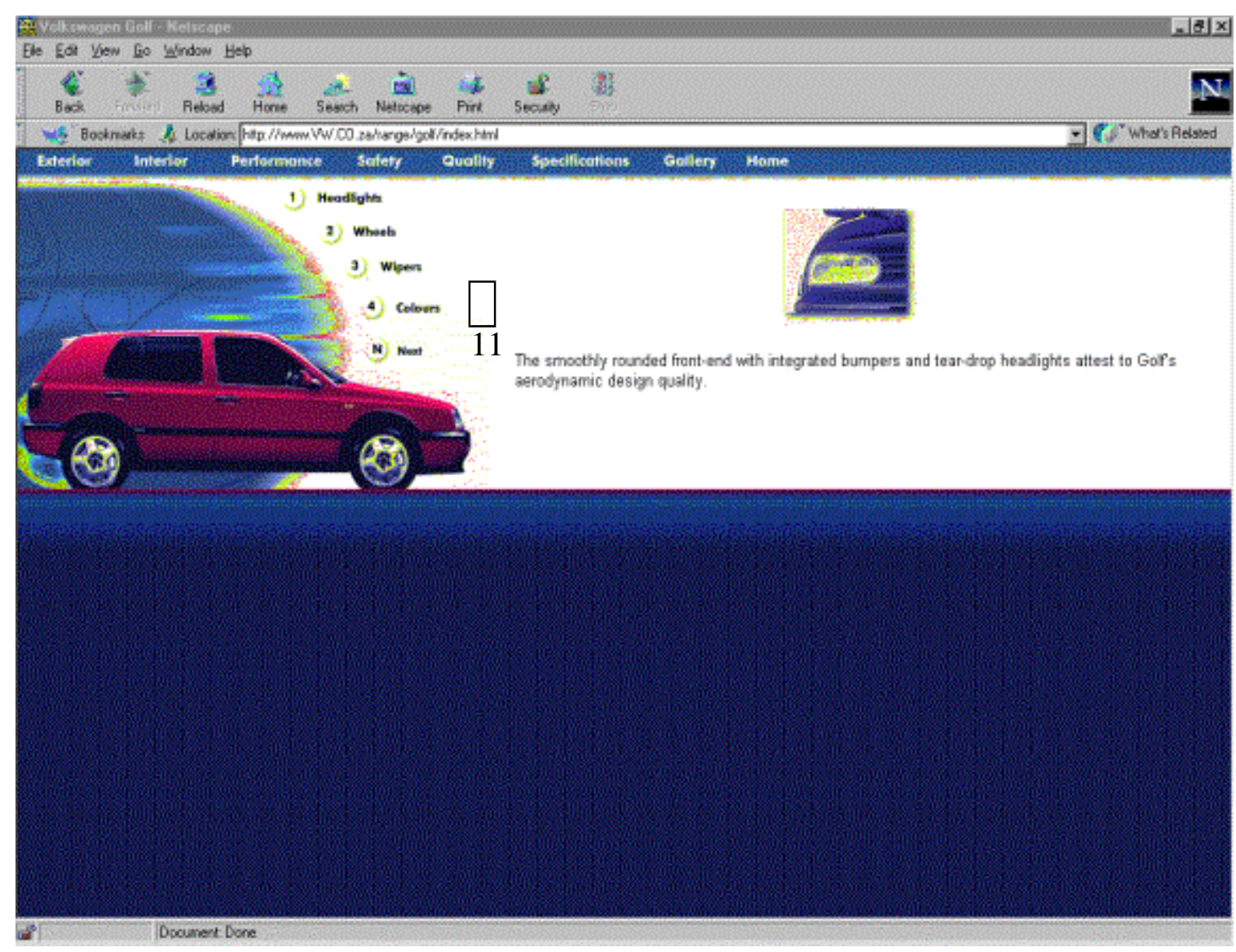

Source: http://www.vw.co.za

A potential customer can click on the 'Golf' image of the product range page and have instant access to information regarding the interior of the Golf, exterior, performance, quality, safety and specifications. In addition to product-related information, the Web site also includes features that are not normally associated with advertising such as the financial calculator.

\subsection{Purchase facilitation strategy}

In addition to information, purchase facilitation can also serve as an incentive to visit as Web site (Barker and Groenne, 1996:103). In contrast with traditional advertising, advertisements on the Web can integrate transactions and even distribution in order to facilitate the purchase. This ability is unmatched in other media, and therefore advertisers whose products score high on the 'possibility of providing purchase facilitation' dimension, can consider this approach.

The following guidelines are applicable when evaluating the possibility of selling a product via the Internet: 
- According to Barker and Groenne (1996:80), products that normally require prepurchase trial are at a disadvantage with respect to buying via the Internet. Vassos (1996:24) also reports that products that need to be physically seen, 'tried on', and or touched before a decision is made is less likely to be sold via the Internet. However, in the cases of certain information-based products, it is possible to let the customer sample the product, for instance by listening to a sound clip from a compact disc or read part of a book.

- The possibility of a direct sell in the advertisement is also especially relevant for products usually sold via mail order such as books, compact disks, appliances and, to a lesser extent, clothing.

- Furthermore, certain goods with a strong brand franchise and standardized products are also suited for online shopping, since trusting the vendor is a critical factor due to the low entry barriers to the medium. For this reason, branded goods and companies with a strong image have an advantage since they are already perceived by the customer to be of high quality. Therefore, customers are likely to trust to be treated fairly by companies commanding a strong brand franchise.

- Standardized goods such as compact discs and books are also well suited for online sales, since the customer knows which quality level to expect.

- In addition to mail order products and products with strong brands, purchase facilitation is a good value strategy for products that can actually be distributed on-line such as smaller software applications, magazines (commonly referred to as e-zines) and reports.

- High-risk goods such as cars or furs are also ill suited for on-line sales, since personal contact often plays an important role when such goods are purchased.

One of the well-known Internet Web sites that integrates the purchase facilitation function with the advertisement is Amazon.com. The home page is presented in the Figure 4. The products sold by Amazon.com falls within the suggested range of products that can be sold via the Internet. Amazon.com uses a combination of the information and purchase facilitation strategies to provide value. Visitors to the site can search the site for books on specific topics, and can retrieve specific information regarding the book such as price, reviews from the publisher and comments from customers. After a specific book has been selected, the customer can purchase the book via the Internet.

Figure 4 Amazon.com home page 


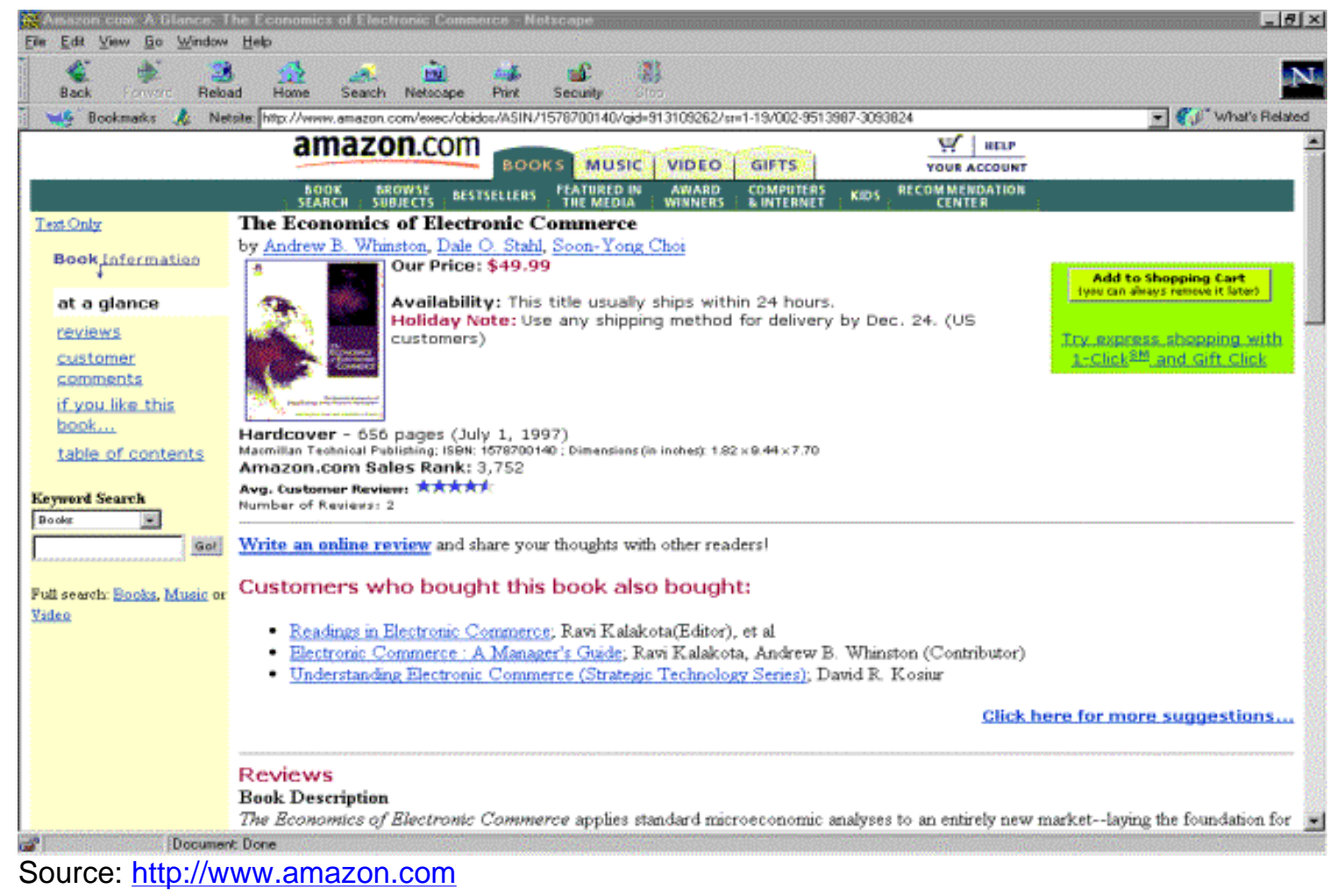

\subsection{Entertainment strategy}

Not all products are high-involvement products and/or provide the possibility of purchase facilitation, but it is possible to create value-based advertising on the Web for products with a low product fit (low involvement, low information intensity and low possibilities of purchase facilitation). Where products with a high product fit (high involvement, high information intensity, high possibilities of purchase facilitation) should normally use an infomercial and/or purchase facilitation approach, these approaches are not likely to be successful for products with a low product fit. This is because it is difficult to offer productrelated information when buyer involvement is low. Thus, another type of value strategy is needed for low-involvement products, namely entertainment.

The advertainment model (using entertainment in the advertisement) adopts different incentives for the customers to visit and stay at the Web site. In contrast with infomercials that focus on product related information, advertainments attract customers by providing entertainment and information that has little to do with the product itself. Because of this, advertainment strategies can theoretically be used for all kinds of products. Further, where infomercials mainly compete for attention with sites with related content, advertainment competes for attention with both related and unrelated sites (Barker and Groenne, 1996:100). Advertainments are also likely to attract surfers rather than searchers, because of the limited connection between the company products and the content offered on the site.

The interactivity of the Web provides unique opportunities for creating advertisements with a high entertainment value and a high degree of user involvement and user activation, for example through quizzes, competitions and games. In addition to providing entertainment, the high-involvement exposures created through advertainment strategies can improve the company’s image and build brand preferences (Barker and Groenne, 1996:101).

Advertainments are a useful strategy for companies manufacturing lifestyle products, e.g. Coca-Cola or Levi's.

Coca-Cola products can be classified as low involvement products, since the purchase of Coca-Cola products is guided rather by habit than active information seeking. Therefore, to 
create value consumers can find various entertainment incentives, for example, customers can send electronic cards to friends, a function that is not related to the Coca-Cola product. The entertainment in this Web site is designed to be product related. For instance, some of the electronic cards have pictures of the Coca-Cola emblem or Coca-Cola products on, and another example is the wording used in the Web site. Words like 'cool' and 'refreshing' which have become synonymous with Coca-Cola and Coca-Cola advertisements appears in the text of the Web site. By employing these non-product related/entertainment strategies, Coca-Cola can use the Web to develop brand preference (Barker and Groenne, 1996:101). The CocaCola Web site is presented in Figure 5.

Figure 5 Coca-Cola home page

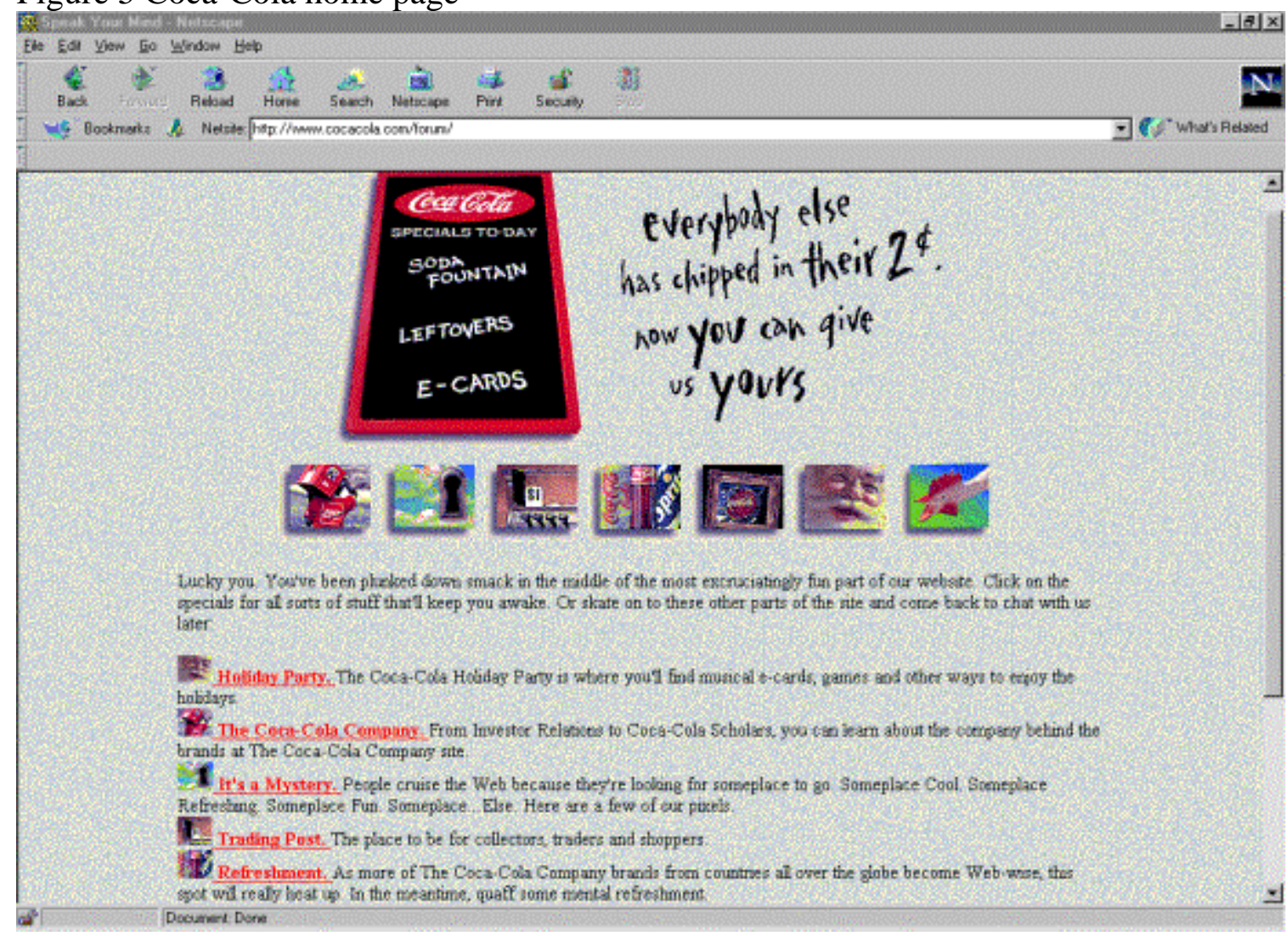

Source: http://www.cocacola.com

\subsection{Comparison between Barker and Groenne's value strategies and the predictors of advertising value}

In summary, Barker and Groenne suggest that providing information, entertainment, or purchase facilitation, in consideration of the degree of buyer involvement, are possible strategies to create value in a Web site. When comparing this approach with the predictors of advertising value determined by Ducoffe, the following conclusions could be presented:

- Ducoffe illustrated that information and entertainment in a Web advertisement predicts value from the consumer perspective. Similarly, Barker and Groenne identified information and entertainment as strategies to provide value for the consumer. Therefore, at this stage it appears that agreement exists that information and entertainment are two possible value strategies.

- Ducoffe did not consider purchase facilitation as a possible value strategy. Two possible reasons for this can be presented. Firstly, purchase facilitation is not normally associated with traditional advertising. Secondly, Ducoffe tested if the predictors of advertising value in traditional media are also predictors of value in Web advertising. Therefore, purchase facilitation was not considered. 


\section{Approach 2: Gascoyne's complete customer-centric solution}

Another approach in developing the value proposition was proposed by Robert Gascoyne. Gascoyne argues that a successful Internet value proposition depends on focusing on a complete customer-centric solution. Gascoyne's approach focuses on providing the customer with all the necessary information to make a buying decision, serving customer values such as convenience, educational marketing and guaranteed fulfilment.

According to Gascoyne the most successful Internet value proposition takes into account four components:

1. Relevant core -competence and compelling solution differentiation;

2. the value of interlinked business partners;

3. customer's changing needs and expectations; and

4. Internet-enabled business capabilities.

This is depicted in Figure 6.

Figure 6: Internet value proposition equation

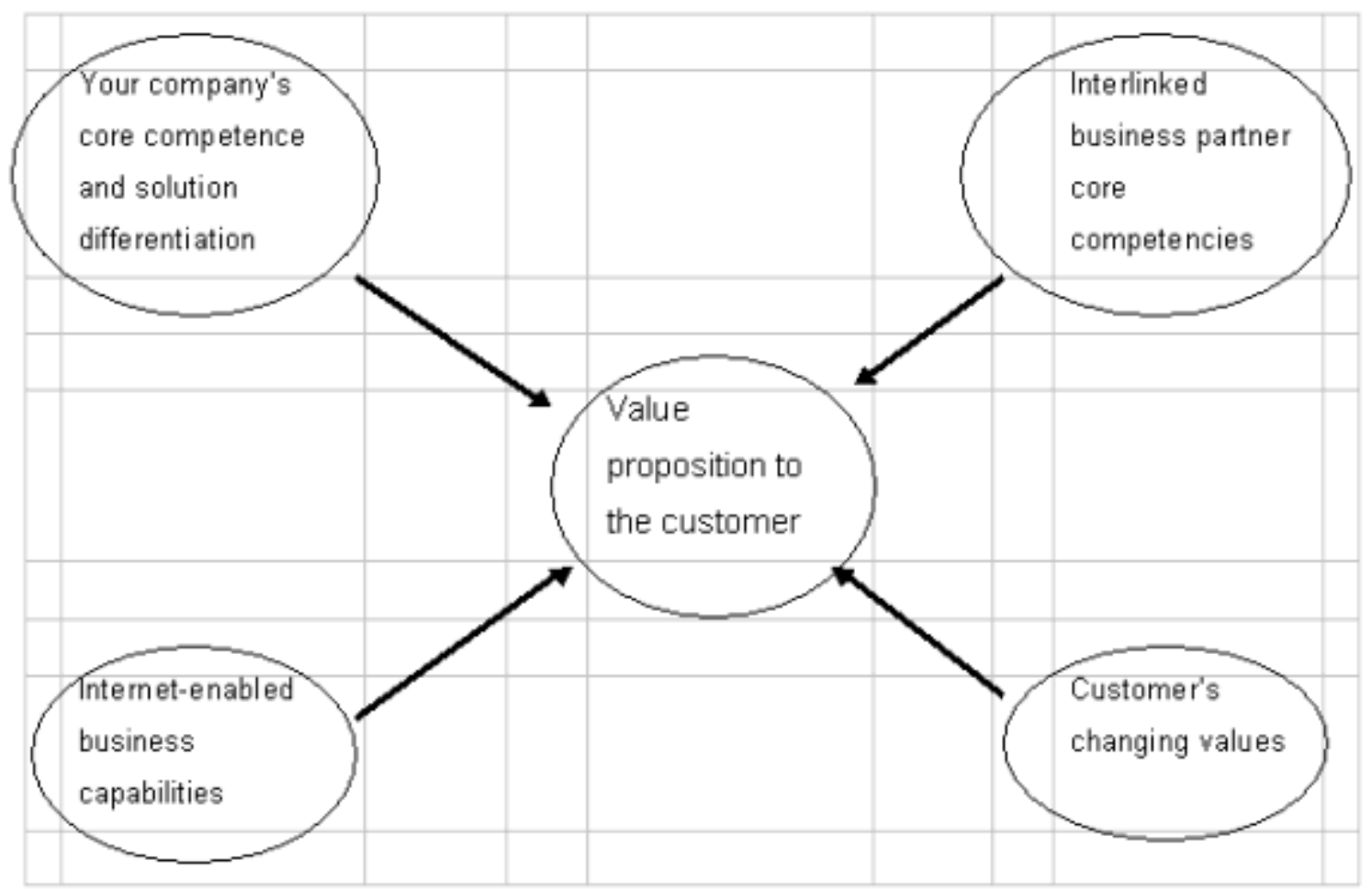

Source: Gascoyne

\subsection{Customer's changing values}

Gascoyne has identified ten specific values of the Internet customer that is necessary to take in consideration in developing the value proposition. They are as follows:

1. Convenience. The increasingly busy life of the customer suggests that convenience will continue to be a prized quality in business and personal transactions. Thus, simplicity on presentation is the key. Gascoyne also reported that studies have shown that graphically rich Internet sites do not generate as much revenue as sites with plainer layouts that are perceived to be more convenient. 
2. Transparency. On-line customers may value a high degree of transparency. In other words, the ability of a user to migrate from one Internet site to another without realising it. Therefore, a business seeking to provide value-added services should examine its ability to offer links to complementary Internet sites. For example, a real estate concern would likely seek to provide links to mortgage brokers and insurers.

3. Guaranteed fulfilment. Customers will increasingly rely on technology to fulfil their needs. Guaranteed fulfilment is closely aligned with immediate satisfaction and, often, immediate gratification. Consequently, potential customers will expect to obtain all the information they need when they visit a site. If the site fails to deliver this expectation, then the customer will leave the site, dissatisfied, for the competitor's site.

4. Security. Security of electronic transactions is if extremely high value to the customer. Urbaczewski argues that the development of security features is an important success issue in electronic commerce. Furthermore, Urbaczewski indicates that a stumbling block to the acceptance of electronic commerce is the perceived lack of security on public networks. Consequently, providing secure commerce will play an important role when purchasing products via the Internet.

5. Education. According to Gascoyne abundant evidence suggests that the educational element of an Internet site is a key element to its success. Therefore, marketers need to use information to educate users on the product benefits, how they compare with other products, and how they should be used.

6. Personalization. The ability to individualize the business's Internet presence for the customer, business partner, vendors, and even employees, will become increasingly important in the future.

7. Proactivity. The ability to move beyond meeting customer needs to actually anticipating those needs is the hallmark of a company striving to meet the challenges of a competitive market. The Internet makes proactivity easier. For example, floral delivery services can maintain key customer information in their databases (e.g. birthdays, anniversaries, holidays) and send reminder messages via e-mail in advance.

8. Timeliness. Timely response and delivery of the product or service becomes increasingly important. In addition, customers also expect updated and immediate information.

9. Choice. With access to products and services from around the globe, today's customer is choosier than before. The Internet allows a customer to collect and assess large quantities of information about specific products and services, allowing a degree of comparison shopping previously unknown.

10. Interaction. Initial evidence suggests that interaction (particularly in a community of interest) provides high value to the customers.

So, too, does the 10TH GVU user survey [online] indicate that specific features of Web vendors are important to Internet Users. According to the information from the User Survey, as indicated in Figure 7, the most important features of Web vendors for Internet users are variety, quality of information, easy ordering, reliability, security and quick delivery.

Figure 7 Important features of Web vendors 


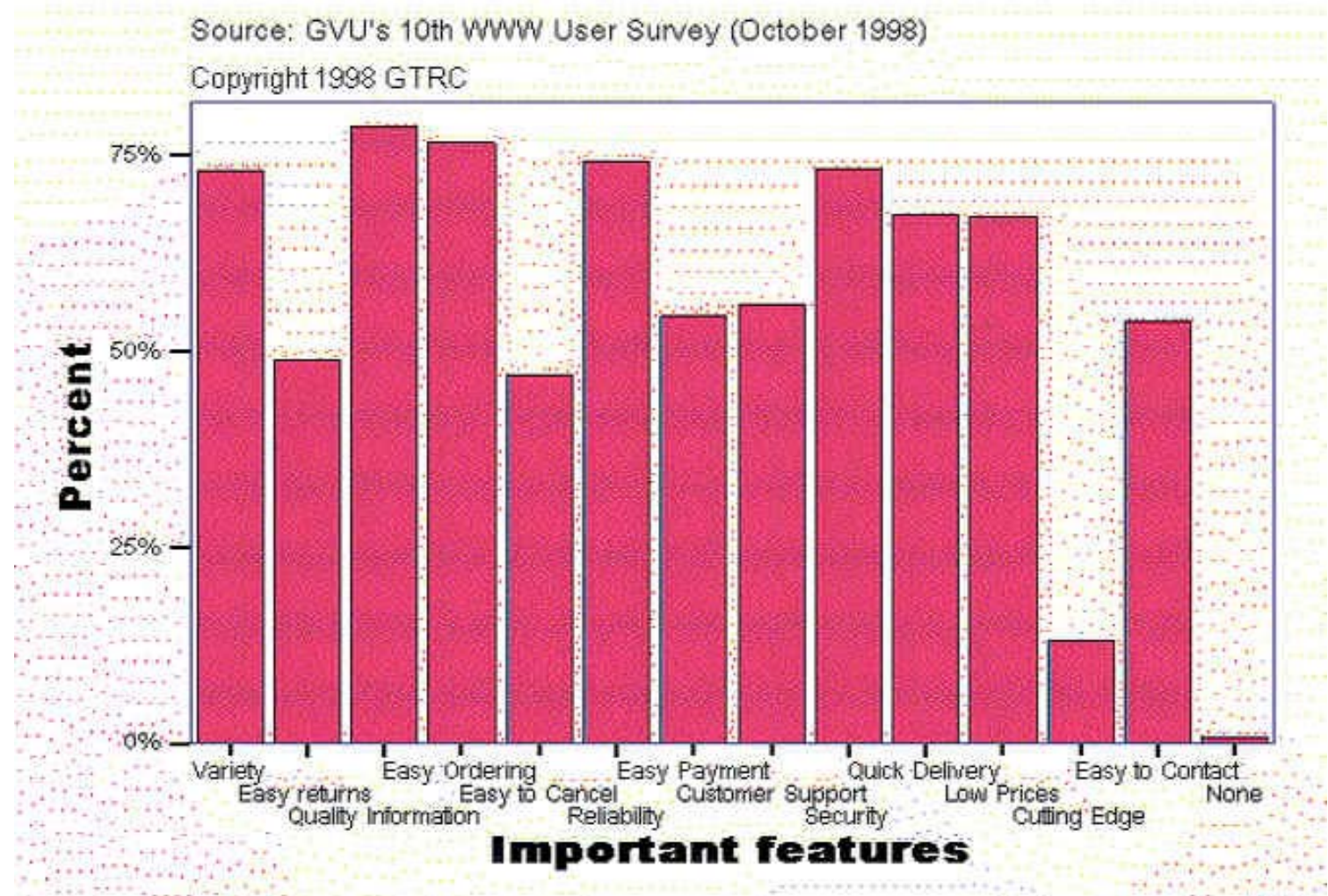

Source: http://www.gvu.gatech.edu/

To sum up, specific values need to be identified and addressed by the other three elements of the value proposition model presented by Gascoyne.

\subsection{Core competence and solution differentiation}

In developing the customer-centric solution, the business must identify the part of the solution they will provide. This is usually manifested in the core competence of the business. According to Gascoyne, the core competencies must be identified from the perspective of the Internet customer, and the relevant core competencies can change quickly from the customer's perspective.

\subsection{Interlinked business partner core competencies}

Komenar (1997:419) reported that the Web site must provide the customer with all the information necessary to make a decision. Therefore, interlinking with business partners is an important tool to provide customers with more-complete business solutions. An example of how interlinking with business partners is used to create the complete solution, is the Toyota South Africa Web site in Figure 8. The Web site provides links to different finance institutions as part of the customer solution. After the potential customer has calculated the instalment, he or she can move on to the next step in the sales cycle, identifying a potential finance institution.

Figure 8 Toyota finance page 


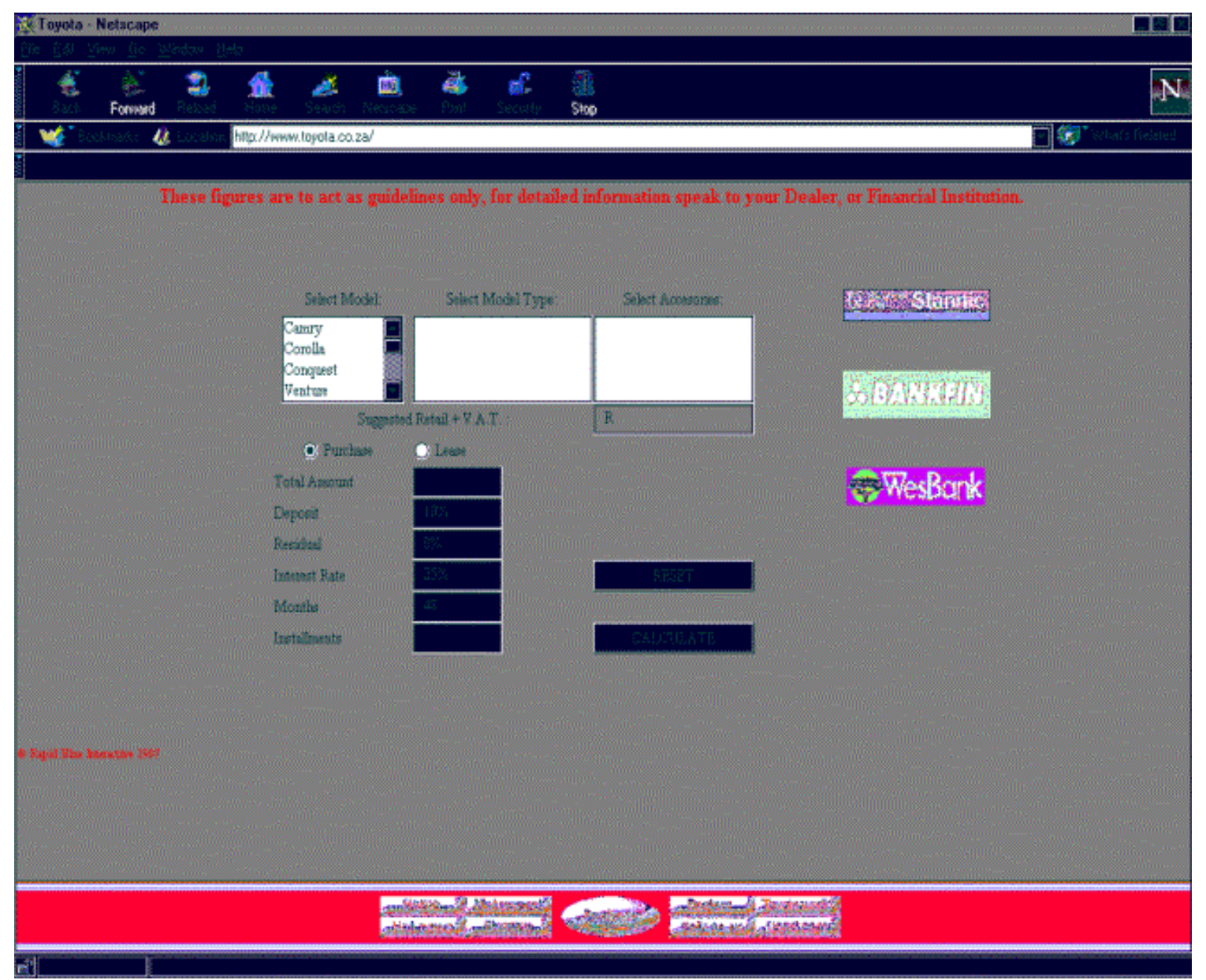

Source: http://www.toyota.co.za

\subsection{Internet enabled business capabilities}

Internet-enabled business capabilities is the fourth part of Gascoyne's value proposition. Ghose and Dau (1998:128) indicated that companies could use the Internet to provide new services inexpensively. A company could, for example, draw on data from its customer base to make available wide-ranging knowledge on some topic. For instance, if a customer has a problem with a product, he or she might consult a site's directory of frequently asked questions to see if others have solved it. Or closer to the advertisement of products, the customer might benefit from knowing how others have used a particular product. Amazon.com encourages customers to post reviews of books they have read for visitors to see, making it possible for customers to scan reviews by peers - in addition to those in publications such as the New York Times - before deciding to buy a book.

\subsection{Comparison between Gascoyne's customer-centric solution and the predictors of advertising value}

When comparing Gascoyne's customer-centric solution and Ducoffe's predictors of value, the following similarities and differences can be identified:

- It appears that Gascoyne's model proposes action steps, rather than strategies, for informativeness and entertainment. For instance, by linking to business partners, more information can be presented to assist the customer in the purchase decision. Thus, the strategy is to provide information and the tactic is to link with business partners. In addition to provide information, the link tactic can also be used to facilitate entertainment, for example linking to sites that contains non-product-related information. 
- Barker and Groenne (1996:95) use the following example to illustrate how an Internet enabled business capability can assist in providing information. 'On the Web, companies have the opportunity to offer customised information in innovative ways, for instance by letting customers access the company's internal databases. When used in this way, the Web advertisement becomes much more than an electronic brochure: It can actually offer customer service. Customers can access information at the advertising site, a procedure that normally requires interaction with company employees. By integrating this kind of information in their Web advertisements, companies are able to deliver value customer service in a way not possible in traditional media.' Thus, Internet enabled business capabilities can also be used to provide information. In addition to providing information, Internet enabled business capabilities can also provide entertainment. Furthermore, online games and contests can also be classified as Internet enabled business capabilities, and can be used to provide entertainment for 'visitors' to a site. To conclude, Internet enabled business capabilities can assist in providing information and entertainment.

- Ducoffe did not consider customer values. Ducoffe's research (1996:26) focused on determining if the predictors of advertising value in traditional media are also predictors of value in Web advertising and therefore did not consider customer values.

- The issue of core competence in the customer solution was also not considered by Ducoffe. Ducoffe did suggest that information was important to create value, but did not elaborate on the type of information.

\subsection{Comparison between Gascoyne's customer centric solution and the three value strategies presented by Barker and Groenne}

When comparing the two approaches, mostly the same conclusions can be drawn as above, with the exception of one. Barker and Groenne proposed that purchase facilitation is a value strategy. In contrast, the model of Gascoyne classifies it is an Internet enabled business capability. The only agreement that does exist is that it contributes to the value of the Web site for the customer. Even so, purchase facilitation cannot be a tactic to supply information or entertainment. Therefore, if it cannot be a tactic, it must be a strategy to create value.

\section{Conclusion}

This study was based on the research, experience and opinions of a number of people. In contrast with the scientific research of Ducoffe, as well as that of Barker and Groenne, the information presented by Gascoyne is based more on experience and opinion. As a result of this mixture between science and real world experience, the findings of this study give useful insight in developing value strategies. The main findings of the study are as follows:

- Providing information is a possible value strategy. The comparison between the two approaches and the predictors of advertising value leads to the conclusion that information is a value strategy. Moreover, the comparisons lead mostly to this important conclusion. The argument regarding tactics to create information contributed to this conclusion.

- Providing entertainment is also a possible value strategy. The comparison between the two approaches and the predictors of advertising value leads to the conclusion that entertainment is a value strategy. In similar fashion to the first conclusion, the comparisons lead mostly to this important conclusion.

- Purchase facilitation is a third possible value strategy. The argument that purchase facilitation cannot be a tactic to create information or entertainment leads to this conclusion. 
- This study also identified that Internet enabled business capabilities are tactics that can be used to create information and entertainment.

- Barker and Groenne also further contributed towards an understanding of the development of value strategies by indicating the implications of product characteristics on the value strategy. Hence, marketing managers need to take product characteristics in consideration when developing possible value strategies.

The implications of this study for marketers are that they need to be aware of the various strategy options available to create value and how they relate to product characteristics. Equally important, marketers need to understand the new business capabilities that the Internet offers to be able to develop Internet enabled business capabilities that will implement the selected value strategy. To conclude, this study indicated that the development of effective value strategies for Web sites is a process that needs to be based on thorough planning.

\section{References}

Barker, C. and Groenne, P. 1996. Advertising on the WWW. Masters thesis, Copenhagen Business School, Copenhagen. [Online] Available WWW: http://test.apl.dk/pg/advertising/.

Berthon, P., Pitt, L.F. and Watson, R.T. 1996. The World Wide Web as an advertising medium: toward an understanding of conversion efficiency. Journal of Advertising Research, 36(1):43-55.

Bush, A.J., Bush, V. and Harris, S. 1998. Advertiser perceptions of the Internet as a marketing communication tool. Journal of Advertising Research, 38(2):17-27.

Ducoffe, R.H. 1996. Advertising value and advertising on the Web. Journal of Advertising Research, 36(5):21-35.

Ghose, S. and Dou, W. 1998. Interactive functions and their impact on the appeal of internet presence sites. Journal of Advertising Research, 38(2):29-43.

Hanson, W. 1999. Principles of Internet marketing. South-Western Publishers.

GVU Internet user survey. [Online] Available WWW: http://www.gvu.gatech.edu.

Lamb, W.L., Hair, J.F. and MacDaniel, C. 1996. Marketing. South-Western College Publishing.

Komenar, M. 1996. Electronic marketing. John Wiley \& Sons.

NUA surveys. [Online] Available WWW: http://www.nua.com.

Schlosser, A.E. and Kanfer, A. 1995/1996. Current advertising on the Internet: the benefits and usage of mixed-media advertising strategies. University of Illinois.

Vassos, T. 1996. Strategic Internet marketing. Que Education \& Training.

\section{Disclaimer}

Articles published in SAJIM are the opinions of the authors and do not 
necessarily reflect the opinion of the Editor, Board, Publisher, Webmaster or the Rand Afrikaans University. The user hereby waives any claim he/she/they may have or acquire against the publisher, its suppliers, licensees and sub licensees and indemnifies all said persons from any claims, lawsuits, proceedings, costs, special, incidental, consequential or indirect damages, including damages for loss of profits, loss of business or downtime arising out of or relating to the user's use of the Website.

ISSN 1560-683X

Published by InterWord Communications for the Centre for Research in Web-based Applications, Rand Afrikaans University 